\title{
Open Heart: Entering the Dynamic of Polyamorous Relationship.
}

\author{
Lucky Juliandino ${ }^{1}$, Dwi Setiawan ${ }^{2}$
}

English Department, Faculty of Languages and Literature, Petra Christian University, Siwalankerto 121131, Surabaya 60236, INDONESIA.

E-mail: m11416046@john.petra.ac.id ${ }^{1}$, dewey@petra.ac.id ${ }^{2}$

\begin{abstract}
Open Heart is a screenplay under a romantic comedy drama subgenre, which recounts a romantic tale about a monogamous, lonely, single man who is struggling to accept and exercise an open heart during a novel participation in polyamory that the woman he falls for is involved with. In this project, I investigated why my protagonist join a polyamorous courtship and how he handles the common hurdles in consensually non-monogamous (CNM) experiences, specifically, jealousy and stigma-based shame. I answered these problems using findings from polyamory, romantic jealousy and Gregory M. Herek's sexual stigma concepts. The results determine that my protagonist only agrees to polyamory out of compliance. Also, in order to solve his plights, he needs to uphold particular management for jealousy and shame. Hopefully, by showcasing these issues around non-monogamy and polyamory, I wish my story could promote a wider understanding, along with uncovering the oppression still targeting them.
\end{abstract}

Keywords: Polyamory, consensual non-monogamy, CNM, romantic comedy, romantic jealousy, sexual stigma

\section{INTRODUCTION}

Polyamory is a growing romantic movement that remains slowly but steadily on the rise in this dawning age and time. Statistically, throughout 2006 to 2015, the masses' curiosity about CNM started to take off based on the surge in Google search for polyamory and open relationships (Mors, 2016, as cited in Baer, 2018). Plus, a study discovered that one in five people have taken part in CNM relations in their lifetime (Haupert, Gesselman, Moors, Fisher \& Garcia, 2017, as cited in Cooney, 2018). Moreover, 31\% of women and 38\% of men showed interest in CNM as an ideal courtship based on a 2016 YouGov poll (YouGov, 2017, as cited in Baer, 2018). Additionally, 4-5\% of the US population are currently implicated in CNM relationships, summing up an approximate 9.8 million people (Sheff, 2019). Furthermore, in support, social media such as Facebook and a dating app called OkCupid have kept up with the time by adding open relationship or CNM as the dating status (Khazan, 2016).

Having laid out the contemporary background of polyamory, to understand it better, Sheff (2016) wrote that it is a form of CNM and romantic pursuit of both emotional and sexual intimacy between more than one consenting partners. Aside from mainly being known for its plural participants, the difference from polyamory with monogamy is its practice. Mainly, the polyamorous technical protocols are complex and not a one-size-fits-all as it is diversely different depending the partners involved and their preferences. Although, a few shared common links from many of my readings listed the most principal rules of conduct for polyamory: negotiation and consent, dignity and respect (Johnson, 2019), faithfulness (Zhu, 2018), transparent communication and honesty (Sheff, 2017), trust (Haslam, 2008) and nonpossessiveness (Johnson, 2019; Attridge, 2013).

Furthermore, in respect to polyamory's types of relationship procedures, they extend into numerous branches: (1) hierarchy or non-hierarchy between primary and secondary partners (Balzarini et al, 2017), (2) mono/poly, a monogamist who engages in a polyamory (Wenzel, 2020), (3) polyaffective, mere friendship between oneself with their partner's 
partner(s) (metamour) (DeLamate \& Plante, 2015) and so on. Pertaining to the multiple partnership, there are also certain amount of formations, for example, some function separately as a couple from other partner(s) (parallel polyamory) (Cooney, 2018), while some in Triad (three people), Quad (four people), or more (Johnson, 2019). Meanwhile, when it comes to the principal impetus for polyamory, it is due to either natural (sexual orientation) or nurtured factors (voluntary choice) (Sheff, 2016). A survey by Anapol (2010) reveals a few real-life voluntary reasons for polyamory, which are: (1) to comply while also wishing it to come into an ending, (2) to respect the partner, (3) to deepen the relationship, etc.

Into the bargain, however intricate yet flexible polyamory may seem at the same time, it still comes with limitations as well as problems too. At the top, Séguin (2017) stated that jealousy is said to be a huge problem that comes and goes. It is inevitable and expected particularly if factors such as (1) favoritism/disproportionate intimacies, or (2) imbalanced time allocation, and many more unmentioned, are present. By definition, romantic jealousy concerns a protective response in reaction to the actual or imagined interloper threatening the fidelity of the pre-formed romantic and sexual courtship (Guerrero, Spitzberg \& Yoshimura, 2004; Bevan, 2004; Pines, 1998). There is also another set of jealousy experienced particularly in polyamory named "polyagony" in which it involves jealousy with the existing and already established partner(s) (Deri, 2011). However, to overcome these feelings, there are several recommended jealousy management: (1) ending the relationship, (2) open communication, (3) reappraising/reevaluating the jealous triggers (Buunk, 1982). In the case of polyagony, the solutions are (1) compersion, an altruistic happiness of the love between one's partner with their other partner, (2) renegotiating the poly terms and agreement for new preferred changes (Rubinsky, 2018; Deri, 2011; Mogilski, Reeve, Nicolas, Donaldson, Mitchell, \& Welling, 2019).

To boot, besides jealousy, another prominent issue in polyamory is stigma and discrimination (polyphobia) (Ferrer, 2018). Herek (2007) described sexual stigma as a negative regard that society holds for sexual minorities, i.e., non-monogamists, etc. For example, the common misconceptions about polyamory are its commitment-phobia, volatility, misogyny, incompetent child-rearing environment, and widepsread transmission of sexual diseases (Sheff, 2018), and the list goes on. Herek theorized that this stigma can manifest further structurally, in the form of institutional disenfranchisement, namely, prejudicial class actions like rejecting child custody, housing, and laying off poly-workers, all of which are still legal in Western countries (Sheff, 2018). He also added that it can also pass on individually within aspects such as aggression (enact stigma), discretion (felt stigma) and self-loathe (internalized stigma). Thus, in order to combat the consequential shame, Herek suggests three solutions which are:

a. Reevaluation/framing shame: reexamining, and abandon learned prejudicial belief systems.

b. Tolerance by association: building interpersonal relationships with the members of sexual minorities will pass down knowledge, lessen sexual prejudice, and self-stigma.

c. Destigmatization: challenging the existing institutionalized, heterosexist regulations and promoting equal rights for sexual minorities to incite cultural change.

With that explained, I plan to utilize the aforementioned conflicts and theories/concepts as the basis of this creative thesis. Owing to the social issues above, it is safe to conclude that they are in a way contributed by the society's awareness at large that is still behind. This being the case, I am intending to explore polyamory in my creative project because of the shortage of mainstream awareness. For instance, there is still a lack of recognition in the media at this time, specifically, cinema in the English language. Also, most of its scarce portrayals of polyamory still mostly depict CNM affairs to mostly end in an eventual separation. Therefore, I intend to 
Juliandino, Setiawan: Open Heart: Entering the Dynamic of Polyamorous Relationship.

showcase via my project that polyamorists can sustain their love lives, along with helping to normalize them that should free them from misapprehension. A research paper supports that onscreen representation of minorities in mass media endorses confidence in the represented and can be hugely educative to everyone in general (Lawson, 2018).

Ergo, I hope my script could be beneficial in this way to its viewers. First and foremost, I particularly aspire to introduce the notion to unknowing polyamorists that love is not only possible by a mere pair of individuals. The second target audience is the already practicing polyamorists, both closeted and open. By seeing themselves represented, I hope the closeted polyamorists could be inspired to proudfully come out, and the openly ones become even prouder. Last but not least, for the third spectator, I intend to fill the informational gap and feasibly serve as an educational entertainment to monogamous people who have misconceptions or lack of knowledge regarding non-monogamy.

However, a couple of things that I do not propose through my project is to convert anyone: the viewers, nor the main character in my narrative to be non-monogamous since he is still monogamous (mono/poly). Furthermore, I am also not planning to condemn monogamy and boast non-monogamy above the former in the process. On the other hand, the subject that I am, indeed, criticizing is mononormativity and its governing presumption for monogamy as the normality (Barker \& Langdridge, 2010, as cited in Ferrer, 2018), which pigeon-holes individuals into just one fixed style of amorous entanglement. Essentially, I once again repeat that I hope I could provide a more insightful representation of the poly community amongst the lack thereof by means of my creative work.

Distinctly, such will fall under the format of a screenplay because it likely becomes a film since it is merely a prototype for a film (Russin \& Downs, 2012). I think films are the most effective form of storytelling in a plethora of ways. For starters, films potentially have an exceptional quality called "cinematherapy" that not only could offer a much quicker go-to for escapism and emotional catharsis, but also promote healing, influence behavioral change, expand new thinking and understanding, and even rehabilitate mental disorders, etc. (Borchard, 2016). Additionally, some extra selling point is that films are more practical and succinct to deliver their messages in a single sitting. Not to mention, movies are more digitally accessible in this golden age for digital media with the help of purchase or rent website services and the everexpanding international and national streaming services.

Having made a case for the screenplay format, I would like to propose rom-com as the genre since my topic revolves around the subject of romantic relationship. In definition, it deals with love in a light-hearted and comical tone (American Film Institute [AFI], 2008, as cited in Grindon, 2011). I suppose the rom-com tone could lighten up the weight of the topic since Batty and Jacey (2015, chap. 1, para. 3) wrote that rom-com is letting the "imagination to play, to create, to take us out of the monotony of humdrum life, and to submerge ourselves unashamedly in feel-good and heartfelt emotions that normal life somehow represses". Also, considering that polyamory is an unfamiliar concept, rom-coms would help send my message more effectively because rom-coms could affect the viewers to become a more sentimental and open-minded character (Abrams, 2016). Notwithstanding, I am aiming to deviate from a frequently-employed rom-com element: "boy meets girl" structure (McDonald, 2007, p. 8) or duo pairing, because polyamory involves numerous partners.

In addition, within the scope of the genre of my choosing, I plan to add a mix of drama whilst benefiting from some facets of the rom-com genre. Dirk (n.d.) posed that drama is a somber depiction of realistic individuals set in conflicting circumstances with internal or external forces. Thus, I want my work to pack more punch by tapping into heavier subjects that touch upon social issues like the alluded problems around polyamory. Though I am not 
suggesting that rom-com does not possess the ability for such but dramatic genre does so sincerely without any sugar-coating. Supporting my argument, Berry (2018, para. 2) wrote that rom-dramedy is mutually humorous and poignant, as well as possesses the capacity to give more of a "therapeutic good".

Without further ado, to get into more details about my writing, its obstacles are going to be based on the statements of the problems that explore the journey and hurdles of navigating polyamorous relationship from a fish out of water vantage point. In specifity, they examine as to why a monogamous person such as my main character, named Adam, participates in a polyamorous dynamic and how he copes with the aforementioned romantic jealousy and stigmabased sexual shame that he experienced during this understaking.

To answer, the purposes of this creative work shows that Adam's taking part in polyamory is out of compliance by his own choice to his love interest, Zooey. Apropos to the jealousy and shame, Adam needs to fully follow the polyamorus ground rules along with implementing the suggested jealousy and shame management as stated in previous paragraphs.

\section{CONCEPTS OF CREATIVE WORK}

\section{Theme}

The first theme is about opening one's own heart and mind. When a person willfully sets aside their bias and arrogance for considering new ideas other than their own or what society has in mind; go through the learning process, take a chance or a leap of faith on a novel concept through a clear, objective lens, they will learn a new outlook and become familiar with different angles of the particular subject. By then, they deserve to make their own personal opinion about it as opposed to solely from societal presumptions or preconceived notions.

Lastly, the second theme is about non-conforming to certain conventions for one's own happiness. It is not news that people have to abide by each of their society's norms to a great degree in order to avoid negative impressions, so much so they even sacrifice their own happiness if their actions cross outside the established convention. Thus, I want to highlight that being true to oneself is much more worthy than pretending to be somebody they are not.

\section{Pitch}

a. Fresh from a breakup with his ex, Adam is in a search for a more compatible partner and eventually meets the right woman, Zooey, who happens to practice polyamory that he is very skeptical about.

b. To be able to date Zooey, Adam pretends to accept her polyamorous courtship until he encounters personal jealousy and stigma that motivate him to secretly separate Zooey with her main partner, Carter.

c. After many failed attempts and a hiatus, Adam's plan finally succeeds but leads to Zooey's discovery of Adam's secret plan, and a fallout between them, all of which prompts Adam to reevaluate, mend the couple back together in the hopes that they will forgive him and take him back.

\section{Plot}

My plot consists of a romantic journey about a recently single and lonely man named Adam who is in search of a great relationship. He later finds himself becomes infatuated with a singular girl, Zooey, yet in a polyamorous, committed relationship with Carter. When she could 
Juliandino, Setiawan: Open Heart: Entering the Dynamic of Polyamorous Relationship.

not split time between Adam, Carter, and her career, they all entertain the idea to establish a Triad pairing. Seeing that Adam still wants to see Zooey, he agrees. Although, while witnessing Zooey's and Carter's intimacy in person, Adam gets jealous, then covertly plots to break them up. However, unbeknownst to Adam, during their togetherness, he surprisingly becomes less jealous when he is included by the couple more in their home lives. Hence, he finds newfound harmony between them, which prompts him to abandon his masterplan for a little while. Yet, when Adam gets jealous again, as well as receives a rude awakening like discrimination from people around him about his CNM relationship, he puts his plan back on motion. When he succeeds eliminating Carter, Zooey continues to engage in polyamorous flings with another man. Consequently, he gets jealous again and returns to execute his covert operation. Only this time, he is caught red-handedly, and as a result, dumped by Zooey. Ultimately, Adam apologizes to Carter and Zooey, and tries to patch things up between them even when he knows they could not reconcile with him right away. The following year, they forgive him as soon as they discover that Adam has redeemed himself by spreading knowledge about polyamory in his documentary series. When they take him back, Adam has learned more from his research on how to minimize his shame and jealousy while preserving and better his relationship with them on the second round and still staying monogamous with mono/poly style with Zooey, a polyamorous lover, and Carter, an ambiamorous partner's partner (metamour).

\section{Characters}

a.

$\operatorname{Adam}(34$ years old)

Adam is a romantic at heart and newly single, lonely young man. He is recently broken up by his longtime girlfriend, Amy, due to his anti-marriage stance that was resulted from his parents' divorce, $50 \%$ of marriage success rate, personal preference, and many others. In spite of this, Adam is not anti-commitment. He still believes in long-lasting partnership instead of matrimony even though he is pushing thirty and constantly being smothered by the cultural expectation to wed by this age. Because of this fact, Adam has difficulty finding a girlfriend aside from other factors such as his idiosyncratic personality, interest, and average appearance, all of which can make him insecure. This temperament can easily be provoked by jealousy and shame. Other than that, Adam is also hypocritical. He does not want to change his idea on antimarriage yet he is compromising other people's conviction of relationships like Amy's marriage goal and Zooey's polyamory.

I formulate the character of Adam as a relatable common, everyday man. He works a 9to- 5 job as an analyst who wishes to pursue a better job, specifically, documentary-filmmaking, which is his passion. In addition, Adam is a symbol for the present-time conventional society and its norm. Automatically, not only is he a conformist, but also monogamous and heterosexual. I formulate him this way because Adam is a representation of the modern monogamous society who has not had experience, and predilection toward CNM.

b. Zooey (32 years old)

Zooey is Adam's newfound love interest. She is an artist from Britain who moved to New York to explore the art scene outside Europe and get away from her overbearing family. She is very unusual, unique and eclectic; has a quirky and bubbly personality, mannerism, and style. Furthermore, appearance-wise, she has a slender figure since she is as beautiful as she is intelligent, thought-provoking, progressive, free-spirited, cultured and so on. On top of that, Zooey has several interests like music, theatre, a little bit of sports, and film, which is a mutual interest she shares with Adam but more with Carter. Philosophically, she is a contrast to Adam who is a conformist. On marriage, Zooey's stance on it is neither anti nor pining for it as a must for she is neutral. 
Moreover, Zooey is an extrovert, hence she is people-oriented. In a way, other than because of her sexual orientation, her extroversion is another main impetus to practice polyamory because she does not want to limit getting to know other people to a certain extent, be it mere friendship or romance.

c. Carter (35 years old $)$

Carter is a handsome, successful and seemingly perfect guy. Physically, he is a wellbuilt, sharp, suave and a well-dressed man. Personality-wise, he is also a kind, open and welcoming character to Adam especially since he is sociable and easily puts people at ease. All of his good qualities make him seem to be too good to be true. Apart from that, he enjoys and frequently partakes in cultural activities as much as Zooey, namely, going to art galleries, broadway shows, etc. Thus, he gets to spend more time with her at times as he has more things in common, and he knows her longer and has a deeper relationship with her than Adam. In addition, Carter is considered to be an ambiamorous (both monogamous and polyamourous).

d. Dave (33 years old)

Dave is Adam's co-worker and best friend from college. He is an unfiltered, emasculating, somewhat typical machismo who loves sports and beers. Physically, he is short and neither ugly nor too good-looking. Despite his look, he has found a partner and happily married. When it comes to Adam's love life, Dave is very supportive and consoling because he wants Adam to have what he has with his wife. As a result, Dave jumps at the chance to be Adam's wingman, accomplice or partner in crime in Adam's ploy, which is also his suggestion.

I created Dave's character as an amplified ripple of voice from the collective status quo as he is a stronger representation of the societal standard and heterosexism than Adam. He can be considered as ignorant, albeit not too blatantly hateful until the end. In addition, Dave follows the norm as Adam, if not more.

e. Evelyn (68 years old)

Evelyn is a widowed, divorced single mother to her only child, Adam. She is a classic mother who looks forward and reminds her son to get hitched and bear children at his certain age because she wants her son to have the complete family package that she could not give to him during her failed marriage. Nonetheless, as somewhat traditional as Evelyn can be, her ideology about certain things wavers between conservative, center and progressive as it is not set in stone. She tries and can be a good mother as much as she possibly can to Adam regardless of political standing.

\section{f. Amy (33 years old)}

Amy is Adam's longtime live-in girlfriend. She is a beautiful, and traditional girl who expects marriage, family and children. She is sweet but can be tough when she needs to. She is patient yet has limitations too. Nevertheless, she was a great girlfriend to Adam, which makes the breakup mostly surprising to him.

g. George (53 years old)

George is Adam's and Dave's boss who is both formal and slightly as friendly as he can be to his employees. He can be firm on work policies and productivity because he is an establishmentarian supervisor. 
Juliandino, Setiawan: Open Heart: Entering the Dynamic of Polyamorous Relationship.

h. Rosalyn (30 years old)

Rosalyn is a loving wife and happily married to Dave. She is a good cook and homemaker. She likes to come to Dave's work to bring him his lunch.

\section{Conflicts}

Throughout my screenplay, there are three step-by-step types of conflict. The first one is man vs. man. A conflict such as this occurs in a circumstance of mismatching goals between different characters (Lamb, 2008). This conflict happens when Adam's goal in wanting to be with Zooey in sole pair differs to Zooey's and Carter's objective that want to be in a polyamorous relationship.

Later, once Adam enjoys his romantic quality time as a throuple, he faces another conflict: man vs. society. According to Gitner (2015), the conflict occurs when the protagonist is placed in opposition with societal norms. Because polyamorous relationship is incongruent with the mainstream custom, Adam's acquaintances, close ones and strangers start to discriminate and stigmatize him for it.

Lastly, the third conflict is man vs. self. This problem arises from the main character's internal turmoil (Lamb, 2019). So, Adam's inner conflict happens when he struggles greatly facing dilemmas within himself, one of which is that he either has to overcome or let romantic jealousy and sexual shame affect him, and so on.

\section{Setting}

As for the location, New York City bears relevance to my story, and aligns with my creative choice. First and foremost, it is because the city is the cultural capital of the world that holds myriads of cultural sights or attractions that would provide interesting dating spots that correspond with the personal interests of my characters.

Secondly, my decision to place the narrative in a Western culture is due to its norm: cohabitation. It is a living arrangement between an unmarried couple, which is "a common part of family formation in the United States and serves as both a step toward marriage and as an alternative to marriage" (Copen, Daniels \& Mosher, 2013, as cited in Aleccia, para. 21). I incorporate cohabitation as a living situation for the long-established polyamorous primary relationship between Zooey and Carter that causes jealousy to Adam, and a personal relationship benchmark that he wants from Zooey, as opposed to marriage.

Next, specifying my screenplay in a Western country such as the U.S. is because there have been sufficient reported datas of stigma, discrimination and bias toward polyamory. Moreover, another basis for New York City backdrop is because I want to showcase how slow the polyamory movement and how far they have to go is for it to still be a subject of intolerance even in a city that is considered as a liberal state, according to Pew Research Center (Desilver, 2014).

Lastly, New York City in my script serves as a symbolism representing Adam's behavior that seems accepting on the surface regarding the polyamory agreement, though underneath, he is sort of bigoted and rejecting. Just like NYC, despite its diverse, progressive and liberal front, it still carries injustice here and there, namely, to CNM polyamory practitioners. 


\section{CONCLUSION}

In conclusion, I will recapitulate how the purposes of my creative work solves the three statements of the problems more detailed through my project. First and foremost, Adam's motivation to self-willingly enter a polyamorous dynamic merely because of his loneliness and desperation to date Zooey while also wishing the CNM with her boyfriend to end (through his scheming). This is motivated by his jealousy and sexual shame. However, after he realizes his mistake in the end, he will shift his intention to the right ones: to respect and deepen the bond with Zooey. Also, I deliberately make use of certain polyamory styles like parallel polyamory before the triad and mono/poly throughout Adam's CNM. They serve as Adam's reason for considering joining CNM as feasible initially because they could make his relationship with Zooey as regular as possible like a monogamous relationship.

Next, Adam tackles jealousy in the end by performing its coping mechanisms in certain scenes of my story. The open communication is enacted by Adam accidentally during a confrontation with Zooey after she catches his ruse. Afterward, he reappraises/reevaluates his jealousy to his mother in a dinner scene because of feeling guilty and remorseful. Next, Adam learns via his research and implicitly applies compersion, renegotiation of poly terms, the polyamory protocols seriously once Zooey and Carter decide to take him back in the end after their discovery of Adam's documentarial work.

Last but not least, Adam controls his stigma-based shame he receives from public reception with tolerance by association from not only knowing Zooey and Carter, but also the poly friends who educate and help Adam for his documentary. Then, he reevaluates/frames his shame during a reflective heart-to-heart with his mother after his fight with Zooey. Finally, as a way to make it up for his mistake and in pursuit of his passion, he destigmatizes polyamory via his documentary. Thus, these are the plenty of scenarios my creative project resolves the proposed thesis problems.

\section{REFERENCES}

Abrams, S. (2016, December 13). Romantic comedies make you a better person, says science. Retrieved from https://www.elitedaily.com/entertainment/film/romantic-comediesbetter-moral-person/1718968

Aleccia, J. (2013, April 4). 'The new normal': Cohabitation on the rise, study finds. Retrieved from https://www.nbcnews.com/healthmain/new-normal-cohabitation-rise-study-finds$1 \mathrm{C} 9208429$

Anapol, D. (2012, January 16). Polyamory in the 21st century: Love and intimacy with multiple partners [e-book]. Retrieved from https://b-ok.asia/book/2285515/ae62dd

Attridge, M. (2013). Jealousy and relationship closeness. SAGE Open, 3(1), 215824401347605. doi:10.1177/2158244013476054

Baer, D. (2017, March. 6). Maybe monogamy isn't the only way to love. Retrieved from https://www.thecut.com/2017/03/science-of-polyamory-open-relationships-andnonmonogamy.html

Balzarini, R. N., Campbell, L., Kohut, T., Holmes, B. M., Lehmiller, J. J., Harman, J. J., \& Atkins, N. (2017). Perceptions of primary and secondary relationships in polyamory. PloS one, 12(5), e0177841. https://doi.org/10.1371/journal.pone.0177841

Batty, C. \& Jacey, H. (2014, November 27). Writing \& selling romantic comedy screenplays [ebook]. Retrieved from https://b-ok.org/book/2 516049/a12f62 
Juliandino, Setiawan: Open Heart: Entering the Dynamic of Polyamorous Relationship.

Berry, J. (2018, August 15). The healing power of the rom-dram, a.k.a. romantic dramedy: A case for how the best romantic dramedies can be excellent therapy. Retrieved from https://thekit.ca/life/culture-life/sad-romantic-comedies-drama/

Bevan, J. L. (2004). General partner and relational uncertainty as consequences of another person's jealousy expression. Western Journal of Communication, 68(2), 195-218. doi:10.1080/10570310409374796

Borchard, T. (2016, June 17). Cinematherapy: The healing power of movies and tv. Retrieved from https://www.everydayhealth.com/columns/therese-borchard-sanitybreak/cinematherapy-healing-power-of-movies-tv/

Buunk, B. (1982). Strategies of jealousy: Styles of coping with extramarital involvement of the spouse. Family Relations, 31(1), 13. doi:10.2307/584196

Cooney, S. (2018, August 27). What monogamous couples can learn from polyamorous relationships, according to experts. Time. Retrieved from https://time.com/5330833/polyamory-monogamous-relationships/

DeLamater, J., \& Plante, R. F. (2015, June 19). Handbook of the sociology of sexualities. Retrieved from https://books.google.co.id/books?id=0d3yCQAAQBAJ\&printsec=frontcover

Deri, J. (2011, July 26). Polyamory or polyagony? Jealousy in open relationships. (Doctoral dissertation, Simon Fraser University) [PDF]. Retrieved from https://core.ac.uk/download/pdf/56375937.pdf

Desilver, D. (2014, August 8). Chart of the week: The most liberal and conservative big cities. Retrieved from https://www.pewresearch.org/fact-tank/2014/08/08/chart-of-the-weekthe-most-liberal-and-conservative-big-cities/\#more-262185

Dirks, T. (n.d.). Drama films. Retrieved from https://www.filmsite.org/dramafilms.html

Ferrer, J. N. (2018). Mononormativity, polypride, and the "mono-poly wars". Sexuality \& Culture, 22(3), 817-836. doi:10.1007/s12119-017-9494-y

Gitner, S. (2015, July 3). Multimedia storytelling for digital communicators in a multiplatform world. Retrieved from https://books.google.co.id/books?id=5AUXCgAAQBAJ\&printsec=frontcover\&source= gbs_ge_summary_r\&cad=0\#v=onepage\&q\&f=false

Grindon, L. (2011, April 18). The Hollywood romantic comedy: Conventions, history and controversies [PDF]. Retrieved from https://b-ok.asia/book/2152982/f39d67

Guerrero, L. K., Spitzberg, B. H., \& Yoshimura, S. M. (2004). Sexual and emotional jealousy. In J. H. Harvey, A. Wenzel, \& S. Sprecher (Eds.), The Handbook Of Sexuality In Close Relationships, 311-345. Retrieved from https://psycnet.apa.org/record/2004-13774-013

Haslam, K. R. (2008, May 15). The 12 pillars of polyamory. Retrieved from http://www.polyamoryonline.org/articles/12pillars.html

Herek, G. M. (2007). Confronting sexual stigma and prejudice: Theory and practice. Journal of Social Issues, 63(4), 905-925. doi:10.1111/j.1540-4560.2007.00544.x

Johnson, M. (2019, March 14). What does it mean to be polyamorous? Retrieved 2020, March 5, from https://www.healthline.com/health/polyamorous\#terms-to-know

Khazan, O. (2016, January 8). OkCupid adds a feature for the polyamorous. Retrieved from https://www.theatlantic.com/technology/archive/2016/01/ok-cupid-is-opening-up-topolyamorous-relationships/423162/

Lamb, N. (2008, December 15). The art and craft of storytelling: A comprehensive guide to classic writing. Retrieved from https://books.google.co.id/books/about/The_Art_And_Craft_Of_Storytelling.html?id=u CBjDwAAQBAJ\&printsec $=$ frontcover\&source=kp_read_button\&redir_esc $=\mathrm{y} \# \mathrm{v}=\mathrm{onepa}$ $\mathrm{ge} \& \mathrm{q} \& \mathrm{f}=$ false

Lawson, K. (2018, February 21). Why seeing yourself represented on screen is so important. Retrieved from https://www.vice.com/en_us/article/zmwq3x/why-diversity-on-screenis-important-black-panther 
McDonald, T. J. (2007, April 10). Romantic comedy: Boy meets girl meets genre (short cuts). Retrieve from https://books.google.co.id/books?id=9BkmkvdPYcC\&printsec=frontcover\&hl=id\&source=gbs_ge_summary_r\&cad=0\#v=onepa ge\&q\&f=false

Mogilski, J. K., Reeve, S. D., Nicolas, S. C. A., Donaldson, S. H., Mitchell, V. E., \& Welling, L. L. M. (2019). Jealousy, consent, and compersion within monogamous and consensually non-monogamous romantic relationships. Archives of Sexual Behavior. 48, 1811-1828. https://doi.org/10.1007/s10508-018-1286-4

Pines, A. M. (1998, June 23). Romantic jealousy: Causes, symptoms, cures [e-book]. Retrieved from https://b-ok.asia/book/1197430/f5d618

Rubinsky, V. (2018). Bringing up the green-eyed monster: Conceptualizing and communicating jealousy with a partner who has other partners. The Qualitative Report, 23(6), 14411455. Retrieved from https://nsuworks.nova.edu/tqr/vol23/iss6/11

Russin, R., \& Downs, W. (2012, July 1). Screenplay: Writing the picture (2nd ed.) [e-book]. Retrieved from https://b-ok.asia/book/3343645/964a8f?regionChanged

Séguin, L. J. (2019). The good, the bad, and the ugly: Lay attitudes and perceptions of polyamory. Sexualities, 22(4), 669-690. https://doi.org/10.1177/1363460717713382

Sheff, E. (2016, March 1). When someone you love is polyamorous: Understanding poly people and relationships. Retrieved from https://books.google.co.id/books?id=72slDAAAQBAJ\&lpg=PP1\&pg=PP1\#v=onepage $\& q \& \mathrm{f}=$ false

Sheff, E. (2017, February 13). What you can learn from polyamory. The Greater Good Magazine. Retrieved from https://greatergood.berkeley.edu/article/item/what_you_can_learn_from_polyamory

Sheff, E. (2018, June 28). Myths about polyamory. Retrieved from https://www.psychologytoday.com/intl/blog/the-polyamorists-next-door/201806/mythsabout-polyamory

Sheff, E. (2018, May 1). Polyagony: When polyamory goes really wrong. Retrieved from https://www.psychologytoday.com/us/blog/the-polyamorists-nextdoor/201805/polyagony-when-polyamory-goes-really-wrong

Sheff, E. (2019, May 27). Updated estimate of number of non-monogamous people in U.S. Retrieved from https://www.psychologytoday.com/intl/blog/the-polyamorists-nextdoor/201905/updated-estimate-number-non-monogamous-people-in-us

Zhu, J. (2018, January). "We're not cheaters": Polyamory, mixed-orientation marriage and the construction of radical honesty. Graduate Journal of Social Science, 14(1), 57-78 [PDF]. Retrieved from http://gjss.org/sites/default/files/issues/chapters/papers/GjSS\%20Vol\%2014$1 \% 20$ Zhu.pdf 